\title{
Vertical velocities associated with gravity waves measured in the mesosphere and lower thermosphere with the EISCAT VHF radar
}

\author{
N. J. Mitchell, V. St. C. Howells \\ Department of Physics, The University of Wales, Aberystwyth, Ceredigion, SY23 3BZ, UK (E-mail:Nick.Mitchell@aber.ac.uk)
}

Received: 13 October 1997 / Revised 30 April 1998 / Accepted: 15 May 1998

\begin{abstract}
The EISCAT VHF radar $\left(69.4^{\circ} \mathrm{N}, 19.1^{\circ} \mathrm{E}\right)$ has been used to record vertical winds at mesopause heights on a total of 31 days between June 1990 and January 1993. The data reveal a motion field dominated by quasi-monochromatic gravity waves with representative apparent periods of $\sim 30-40 \mathrm{~min}$, amplitudes of up to $\sim 2.5 \mathrm{~m} \mathrm{~s}^{-1}$ and large vertical wavelength. In some instances waves appear to be ducted. Vertical profiles of the vertical-velocity variance display a variety of forms, with little indication of systematic wave growth with height. Daily mean variance profiles evaluated for consecutive days of recording show that the general shape of the variance profiles persists over several days. The mean variance evaluated over a $10 \mathrm{~km}$ height range has values from $1.2 \mathrm{~m}^{2} \mathrm{~s}^{-2}$ to $6.5 \mathrm{~m}^{2} \mathrm{~s}^{-2}$ and suggests a semi-annual seasonal cycle with equinoctial minima and solsticial maxima. The mean vertical wavenumber spectrum evaluated at heights up to $86 \mathrm{~km}$ has a slope (spectral index) of $-1.36 \pm 0.2$, consistent with observations at lower heights but disagreeing with the predictions of a number of saturation theories advanced to explain gravity-wave spectra. The spectral slopes evaluated for individual days have a range of values, and steeper slopes are observed in summer than in winter. The spectra also appear to be generally steeper on days with lower mean vertical-velocity variance.
\end{abstract}

Key words. Meteorology and atmospheric dynamics (middle atmosphere dynamics; waves and tides)

\section{Introduction}

Gravity waves play an important role in the dynamics of the middle atmosphere. The waves are now known to

Correspondence to: N. J. Mitchell transport energy and momentum from their loweratmosphere sources and deposit them at greater heights. Modelling studies have revealed that the vertically transferred horizontal momentum profoundly influences the circulation of the mesosphere/lower-thermosphere (MLT) region, decelerating the atmospheric zonal flow away from radiative-equilibrium values, closing the mesospheric jets and inducing a meridional circulation which ultimately cools the summer mesopause to extremely low temperatures through the consequent ascent of air required by continuity considerations (e.g. Houghton, 1978; Lindzen, 1982; Holton, 1982, 1983; Matsuno, 1983; Dunkerton, 1982; Miyahara, 1984; Holton and Zhu, 1984; Garcia, 1989; McIntyre, 1989). The turbulence arising from gravity-wave breaking processes is also important in the transport of heat and constituents. The temporal and geographic variations in gravity-wave fluxes thus contribute to the variability of large-scale properties of the atmosphere. Attempts to understand and model the middle atmosphere therefore require detailed information about properties of the gravity-wave field.

The majority of recent studies of gravity waves in the middle atmosphere have been made primarily at midlatitudes and have employed either Rayleigh and sodium lidars to measure perturbations of temperature and density (e.g. Gardner et al., 1989; Mitchell et al., 1991; Wilson et al., 1991; Meriwether 1993; Senft et al., 1993; Meriwether et al., 1994) or MF, MST and incoherent scatter radars to measure wind perturbations (e.g. Vincent and Reid, 1983; Meek et al., 1985a, b; Vincent and Fritts, 1987; Fritts and Yuan, 1989; Rüster and Reid, 1990; Fritts et al., 1992; Nakamura et al., 1993; Gavrilov et al., 1995). However, despite the considerable body of these latter radar observations, the great majority of such studies have concerned measurements of horizontal winds only. The fact that the vertical-wind perturbations associated with gravity waves are usually an order of magnitude smaller than the horizontal winds makes these measurements technically difficult, and even at MLT heights the vertical 
motions are expected to have amplitudes of only a few $\mathrm{m} \mathrm{s}^{-1}$ at most. An additional limitation is the very limited temporal and spatial coverage offered by some of the techniques able to make such measurements. Consequently, gravity-wave vertical motions at MLT heights have been investigated by only a very limited number of studies (e.g. Reid, 1987; Meek and Manson 1989; Fritts et al., 1990; Fritts and Hoppe, 1995; Hoppe and Fritts, 1995).

Gravity waves occur at scale sizes too small to be resolved in current GCMs and so the parameterisations of the gravity-wave field is an important problem for such models encompassing the MLT region (e.g. Hines, 1997a, b). A key aspect in such parameterisations is an understanding of the nature of gravity-wave spectra and of the physical processes shaping the spectra. Gravitywave spectra have been known for a number of years to have a simple "universal" power-law form at vertical wavenumbers above a critical value (VanZandt, 1982; Smith et al., 1987). The spectral region over which the power-law form holds is taken to represent saturated waves and numerous observations have revealed a form in which the power spectral density of horizontal winds expressed in terms of vertical wavenumber, $F_{u}(m)$, varies with vertical wavenumber, $m$, as $F_{u}(m) \propto m^{-3}$ (VanZandt, 1982).

A number of theories invoking different physical mechanisms have been advanced to account for the observed spectra, including theories based on linear instability (Dewan and Good, 1986; Smith et al., 1987), diffusive damping (Weinstock, 1990), Doppler spreading (Hines, 1991), saturated-cascade processes (Dewan, 1994) and diffusive filtering (Gardner, 1994). These theories are all successful in accounting for the observed spectral amplitudes and slopes when the spectra are those of fluctuations in horizontal velocity or temperature, and so observations of these quantities cannot be used to distinguish between the theories. However, the vertical-wavenumber spectra of vertical velocities predicted by at least some of the theories for saturated waves are significantly different, and so such observations can in principle be used as a test of saturation theories (for example, see the extensive discussion of Gardner, 1996).

In this study we report observations of the verticalvelocity field made using the EISCAT VHF incoherent-scatter radar. Previous studies of the vertical motions associated with gravity waves made using this instrument have employed measurements of very high time resolution, but of durations limited to a few hours (e.g. Fritts et al., 1990; Fritts and Hoppe, 1995; Hoppe and Fritts, 1995). In the present study a much larger data set of lower time-resolution measurements made on a total of 31 days is used to investigate a number of properties of the vertical motions due to gravity waves at mesopause heights. The general character of the waves observed are described and the variance of vertical velocities is used as a tracer of wave activity across the height range observed. Spectra of vertical velocities in terms of vertical wavenumber are presented and the availability of data from different seasons, and from short runs of consecutive days of recording, allows an investigation of the seasonal and day to day behaviour of some aspects the vertical-velocity field.

\section{Measurements and data analysis}

The EISCAT VHF radar used in this study is located at $69.4^{\circ} \mathrm{N}, 19.1^{\circ} \mathrm{E}$, near Tromsø in Norway. The radar operates at a frequency of $224 \mathrm{MHz}$ and has a mean power output of about $0.3 \mathrm{MW}$. The data were recorded with EISCAT Common Program 6 which uses a single vertical beam and can measure vertical winds between about $74-97 \mathrm{~km}$, however, no information is provided about horizontal winds or temperatures. The range gates used correspond to a vertical resolution of 1.05 $\mathrm{km}$ and the data were pre-integrated in time to give samples every $5 \mathrm{~min}$. The lowest height gate corresponded to a height of $75.0 \mathrm{~km}$, and usable signal was rarely returned above about $97 \mathrm{~km}$, so that at most about 21 consecutive height gates of data were available. In each case, the quality of the fit to the returned spectrum was used to provide a value for the uncertainty associated with each velocity determination. In the work reported here the decision was made to reject all data points with velocity uncertainties in excess of $0.5 \mathrm{~m} \mathrm{~s}^{-1}$.

Vertical winds were recorded on a total of 31 days between June 1990 and January 1993. Most of data form short series of several consecutive days of observation. The lengths of the continuous sections of data recording were $6,4,3,3,3,2,2,2,2,2,1,1$ days. The dates of the individual observation sessions are given in Table 1 . Not all the days of observation recorded signal satisfying the above criterion in all height gates at all times, and Table 1 also indicates for each day the percentage of the 6912 possible data points over $24 \mathrm{~h}$ between 75 and 100 $\mathrm{km}$ which yielded usable data. From the values in Table 1, it is clear that some days of observation yielded a comparatively limited number of data points. In general, this was due to curtailment of recording outside of a limited number of hours in the particular day, rather than patchy data throughout the day.

\section{General characteristics of the vertical motion field}

Examples of the vertical-velocity fields recorded are presented in Fig. 1a, b as time-height contour plots. No filtering in time or height has been applied to the data, which were recorded over the two continuous 24-h periods covering 31 July 1992 (Fig. 1a) and 18 March 1991 (Fig. 1b). Note that the figures are plotted on different velocity scales in order to highlight details of each data set. Both sets of data display general characteristics typical of all the wave fields recorded in this study.

Considering the data for 31 July 1992, the motion field is seen to be dominated by short-period oscillations, with only limited indications of longer-period 
Table 1. Dates of EISCAT VHF Common Program 6 vertical wind data. The percentage of usable data points is indicated after each date

\begin{tabular}{ll}
\hline 1990 & \\
June & $12(53 \%), 13(22 \%)$ \\
July & $30(21 \%), 31(74 \%)$ \\
August & $1(10 \%), 27(34 \%), 28(30 \%)$ \\
September & $20(18 \%)$ \\
November & $20(15 \%), 21(38 \%)$ \\
1991 & \\
February & $12(10 \%), 13(54 \%), 14(7 \%), 20(19 \%), 21(25 \%)$ \\
March & $17(30 \%), 18(84 \%), 19(70 \%), 20(37 \%)$ \\
June & $4(52 \%)$ \\
1992 & $30(37 \%), 31(83 \%)$ \\
July & $27(34 \%), 28(73 \%), 29(51 \%)$ \\
October & \\
1993 & $20(10 \%), 21(5 \%), 22(53 \%), 23(42 \%), 24(52 \%)$, \\
January & $25(22 \%)$ \\
&
\end{tabular}

motions. An example of the latter is the suggestion of a descending phase front at heights between about 88-96 $\mathrm{km}$ from about 06:00 to 12:00 UT. The dominant, shorter-period motions appear to be quasi-monochromatic gravity waves with amplitudes of up to $\sim 2.5 \mathrm{~m} \mathrm{~s}^{-1}$ and periods of $30-40 \mathrm{~min}$. The wave events appear to have durations of up to about $8 \mathrm{~h}$ (e.g. the quasimonochromatic wave maximising at heights near 84 $\mathrm{km})$. In all cases the vertical wavelengths appear to be very large, with the phase fronts being, in most cases, effectively vertical. The vertical coherence of the motions is striking, with individual phase fronts appearing over vertical extents of some $10 \mathrm{~km}$ or so. Significantly, wave amplitudes do not appear to increase systematically with height, and, except in isolated episodes, there is little sign of the $e^{(z / 2 H)}$, amplitude growth associated with energy-conserving motions. Wave activity appears to be highly variable over both the height and time range observed. For instance, compare the strong wave activity centred at heights near $84 \mathrm{~km}$ at 09:00 UT, where velocities are recorded of up to $\pm 2.5 \mathrm{~m} \mathrm{~s}^{-1}$, with the quiescent wave field between $\sim 88-94 \mathrm{~km}$ at the same time, where amplitudes are $<1 \mathrm{~m} \mathrm{~s}^{-1}$.

The data for 18 March, 1991 show a broadly similar pattern of vertical phase fronts. However, the amplitudes are significantly reduced compared to those for 31 July, 1992 except for larger amplitude motions at all heights before about 02:00 UT, and the descending region of higher amplitudes starting above $95 \mathrm{~km}$ at the start of the day and slowly descending after about 10:00 UT to $\sim 90 \mathrm{~km}$ by 20:00 UT.
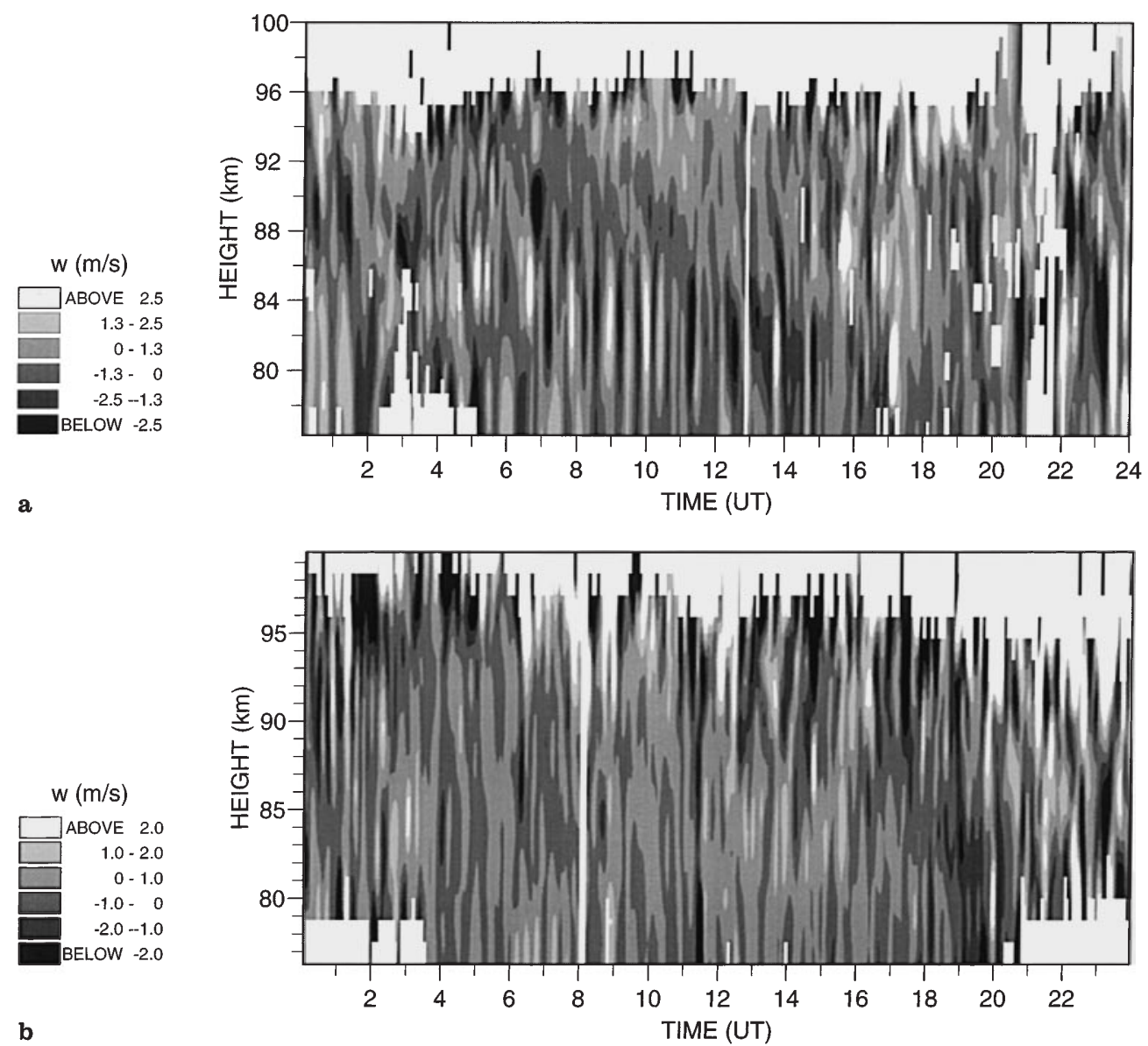

Fig. 1. Time-height contours of vertical velocity for data recorded on a 31 July, 1992, and b 18 March, 1991. Note the different velocity scales used 
This pattern of motion is in marked contrast to that of horizontal winds revealed throughout the mesosphere by radar wind measurements (e.g. Manson, 1990; Nakamura et al., 1993), throughout the upper stratosphere by lidar measurements of temperature and density perturbation (e.g. Gardner et al., 1989; Mitchell et al., 1991; Wilson et al., 1991) and throughout the lower stratosphere by lidar and MST/ST-radar measurements (e.g. Meriwether, 1993; Mitchell et al., 1994). In these measurements the motion field is found to be dominated by quasi-monochromatic waves with periods comparable to the inertial period and vertical wavelengths ranging from $\sim 2 \mathrm{~km}$ in the lower stratosphere to $\sim 15-20 \mathrm{~km}$ at mesopause heights.

In a number of the longer continuous data intervals considered here there are episodes in which a wave appears confined to a particular height range for several hours and has an amplitude which becomes very small or zero at the edges of this range. An example can be seen in Fig. 1a from about 06:00 to 13:00 UT centred at heights of $\sim 83 \mathrm{~km}$. The data for this event is presented in more detail as a time-height contour map of vertical velocity for times between 06:00-13:00 UT and heights between $\sim 77-90 \mathrm{~km}$ in Fig. 2. Of particular interest is the way in which the wave's amplitude appears to decrease rapidly from a maximum of about $2.5 \mathrm{~m} \mathrm{~s}^{-1}$ at $\sim 83 \mathrm{~km}$ to very small amplitudes near $\sim 88 \mathrm{~km}$.

To investigate this behaviour further, amplitudes in each height gate were calculated by least squares fitting a sine wave to the six-hour time interval specified. For each height gate the period of the fitted function was varied until a maximum in amplitude resulted. The wave amplitudes for each height gate derived by this method are presented as a function of height in Fig. 3. Figure 3 clearly shows the rapid rise and curtailment of wave amplitude with height, with wave activity essentially confined between heights of $\sim 78-87 \mathrm{~km}$.

Also indicated on Fig. 3 are four predicted waveamplitude growth curves, initiated from the measured wave amplitude of $0.6 \mathrm{~m} \mathrm{~s}^{-1}$ at a height of $77.7 \mathrm{~km}$. The growth curves are calculated assuming a simple $e^{(z / 2 H)}$ amplitude growth in an isothermal atmosphere at the indicated temperatures of $180,160,140$ and $120 \mathrm{~K}$. It can be seen from Fig. 3 that the wave grows with height more rapidly than would be the case for a conservative motion in an atmosphere at any credible mesopauseregion temperature. This, combined with the vertical phase coherence strongly indicates that the wave is in fact ducted. Unfortunately, no information is available about the temperature or horizontal wind structure of the atmosphere for the data considered here, so the suggestion of ducting cannot be directly confirmed for this example.

It has recently become recognised that the middle atmosphere provides an environment rich in the temperature and wind structures capable of ducting gravity waves. Ducts can be formed by either Doppler or thermal processes. In the case of Doppler ducts, Doppler shifting increases a wave's intrinsic frequency to a value above that of the Brunt-Vaisala frequency, $N$, outside of the duct. Chimonas and Hines (1986) described the behaviour of Doppler-ducted gravity wave and reported several examples of waves apparently so ducted at tropospheric heights. Similarly, thermal ducts may be formed when fluctuations of $N$ with height, perhaps caused by wave-induced perturbations of the background temperature gradient, trap a wave within a layer of atmosphere where at immediately greater and lesser heights the value of $N$ is lower than the wave frequency. Lidar observations have in fact revealed temperature lapse rates approaching the adiabatic in the upper mesosphere (e.g. Wilson et al., 1991; Meriwether et al., 1994), and as temperature lapse rates approach the adiabatic, the associated value of $N$ tends towards zero, so gravity waves of even middle periods can become trapped in a duct bounded by such regions.

Radar studies of the vertical winds associated with gravity waves have usually used MST or ST radars and focused on tropospheric or lower stratospheric heights. A comparatively limited number of such studies have been made of waves at mesopause heights. In this latter

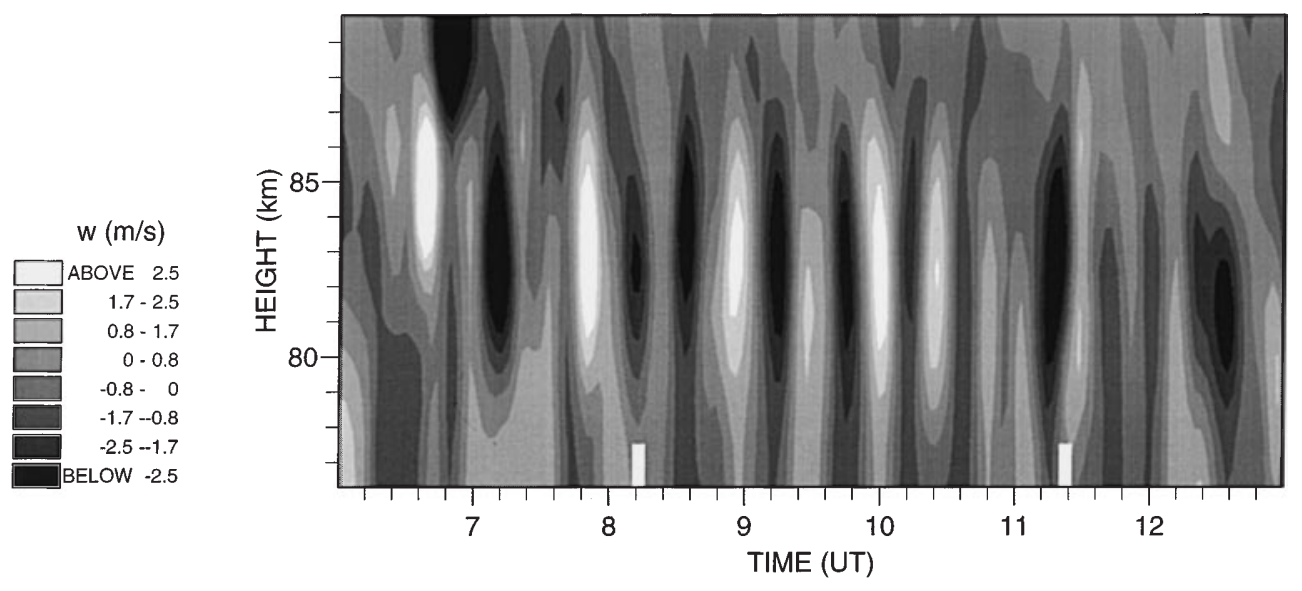

Fig. 2. Time-height contours of vertical velocity for data recorded on 31 July, 1992 between 06:0013:00 UT at heights of 76-90 km 
group are studies of summer mesopause-region vertical winds made using the EISCAT VHF radar by Fritts et al. (1990), in which vertical winds measured with a 10 $\mathrm{s}$ time resolution were recorded for a total of $36 \mathrm{~h}$ on nine days in June and July 1987. Data were also used in their study from 3 days of recording with the SOUSY VHF radar. Hoppe and Fritts (1995) and Fritts and Hoppe (1995) again used EISCAT VHF data to measure vertical mesopause-region winds on one day in June 1988, this time under PMSE conditions. The strong scatter from the PMSE allowed a time resolution of $2 \mathrm{~s}$. The data were recorded in two intervals, one of about $3 \mathrm{~h}$, the other of $1 \mathrm{~h}$ following after a gap of $1 \mathrm{~h}$. In these studies, wave motions with similar periods, vertical coherence and vertical wavelengths to those reported here were identified by the authors in at least some of the data.

Our observations, based on a longer data set covering winter and equinoctial conditions as well as summer, suggest that this pattern is representative of the mesopause region throughout the year. However, there are some differences apparent in comparing the highresolution studies described above with our observations. In particular, the study of Fritts et al. (1990) found vertical velocities up to $\sim 10 \mathrm{~m} \mathrm{~s}^{-1}$, a factor 3 greater than recorded in our lower resolution data. The higher velocities may simply reflect a particularly active day, or may be a product of the different time resolutions. Also, an example of high-frequency waves (wave periods $\sim 1-10 \mathrm{~min}$ ) presented by Hoppe and Fritts (1995), where the authors interpret the vertical phase coherence over some $7.2 \mathrm{~km}$ of altitude as possible evidence of ducting, does not display the approximately Gaussian profile of amplitude with height evident in our data for the event described above and displayed in Fig. 2 and 3.

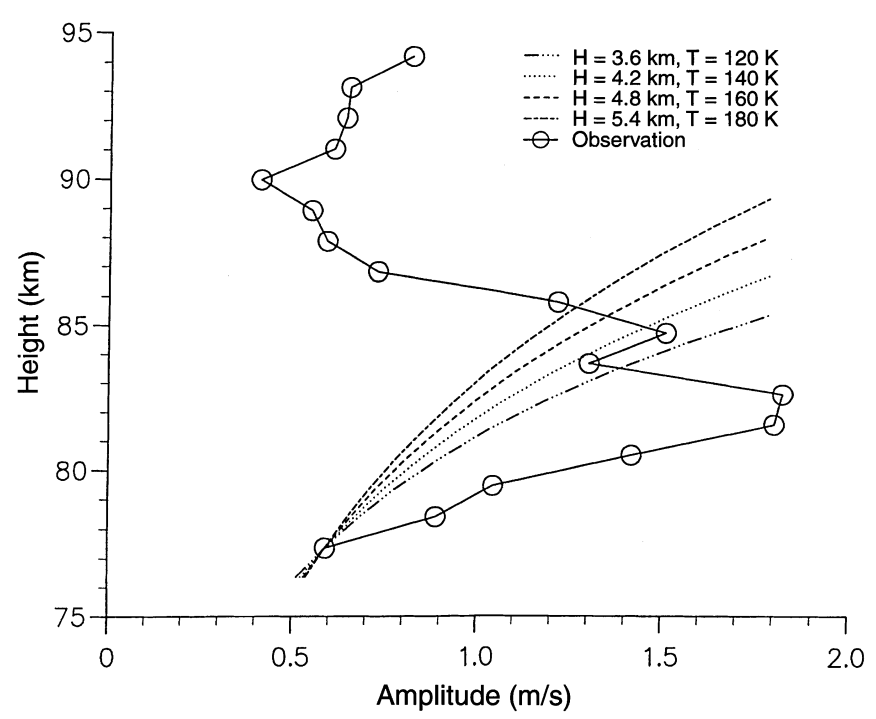

Fig. 3. The amplitude-height profile for the quasi-monochromatic gravity wave observed between 06:00-12:00 UT on 31/7/92. Also indicated are the predicted amplitude growth curves for temperatures of $180,160,140$ and $120 \mathrm{~K}$ isothermal atmospheres
Further evidence that ducted motions may be common at mesopause heights has been provided by the combined MF radar and all-sky nightime airglow CCD imager study reported by Taylor et al. (1995), in which the authors demonstrated that small-scale waves exhibiting highly coherent phase structures observed at four different emission altitudes were Doppler ducted.

\section{Vertical profiles of velocity variance}

Variance of the vertical velocity in each height gate provides a measure of wave activity. The vertical profile of variance can be used as a tracer to give insight into physical processes within the wavefield. For each of the 31 days of data, the mean profile of vertical-velocity variance was calculated. A variety of different types of variance profile are observed, and Fig. $4 \mathrm{a}-\mathrm{d}$ presents four representative examples of vertical profiles of variance between 76-95 km from 4 June 1991, 31 July 1990, 27 August 1990 and 25 January 1993, respectively. In each case, all the data recorded in the indicated 24-h interval are considered, so the curves incorporate contributions from all waves present. It is clear from Fig. 4 that a wide variety of forms of variance curve are observed.

The example for 4 June 1991 (Fig. 4a) reveals a quiescent wave field with approximately constant variance values $\sim 1 \mathrm{~m}^{2} \mathrm{~s}^{-2}$ at all but the greatest heights. The example from 31 July 1990 (Fig. 4b) also reveals a wave field which demonstrates little growth with height, except above $\sim 91 \mathrm{~km}$, however, in this case the wave field is considerably more energetic with variances of $\sim 3-5 \mathrm{~m}^{2} \mathrm{~s}^{-2}$ over most of the height range. A significantly more energetic wave field is revealed in the data for 27 August 1990 (Fig. 4c), where the variance increases in an approximately linear fashion from values of $\sim 2 \mathrm{~m}^{2} \mathrm{~s}^{-2}$ near $76 \mathrm{~km}$ to $\sim 15 \mathrm{~m}^{2} \mathrm{~s}^{-2}$ near $95 \mathrm{~km}$. A more complicated structure is displayed in the data for 25 January, 1993 (Fig. 4d) in which the variance rises from values near $3 \mathrm{~m}^{2} \mathrm{~s}^{-2}$ at $76 \mathrm{~km}$ to a maximum of $\sim 12$ $\mathrm{m}^{2} \mathrm{~s}^{-2}$ near $89 \mathrm{~km}$ then decreases to values near $2 \mathrm{~m}^{2} \mathrm{~s}^{-2}$ near $95 \mathrm{~km}$.

In two of the short series of consecutive days of recording it was noticed that the vertical profiles of vertical wind variance tended to have a similar shape over a time scale of days. An example is presented in the series of four daily mean variance curves calculated for each day in the period 17-20 March 1991 shown in Fig. $5 \mathrm{a}-\mathrm{d}$. In these four profiles a region with variance values fluctuating between $\sim 2-5 \mathrm{~m}^{2} \mathrm{~s}^{-2}$ extends to heights of about $86 \mathrm{~km}$ with little indication of any systematic growth, above which the variance increases rapidly with height. A similar sequence of profiles for the period 21-25 January 1993 is presented in Fig. 6a-e, in which variances rise from values of about $5 \mathrm{~m}^{2} \mathrm{~s}^{-2}$ or less to values of $>10 \mathrm{~m}^{2} \mathrm{~s}^{-2}$ at heights near $90 \mathrm{~km}$ before declining again at greater heights. In each of these two series the general shape of the variance profiles remains similar from day to day. A possible 

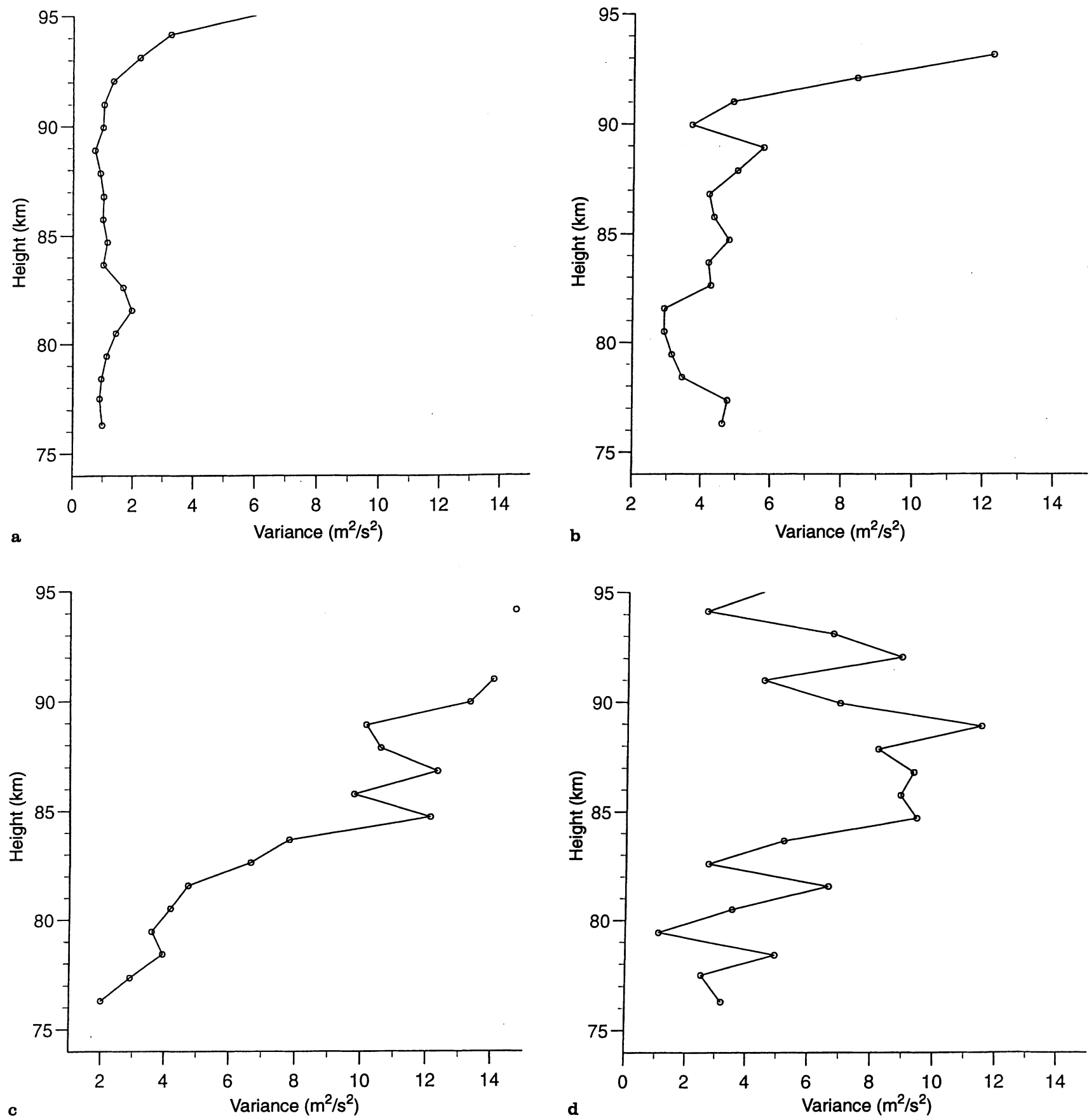

Fig. 4. Profiles of the daily-mean variance of vertical velocity for a 4 June, 1991; b 31 July, 1990; c 27 August, 1990 and d 25 January, 1993

reason for this behaviour is the background structure of wind and/or temperature, but in the absence of this information it is not possible to investigate the phenomenon fully.

The mean variance over an arbitrary height range, evaluated as a function of time, can be used to investigate the seasonal behaviour of wave activity. The averaging over a height range is necessary because of the small-scale fluctuations in the vertical profiles of variance when this quantity is evaluated as a daily mean for each height gate. Figure 7 presents the mean variance over the height interval $76-86 \mathrm{~km}$ evaluated for each of the 31 days of observation plotted against day number in the year. The upper limit was selected because some of the vertical profiles of variance change character at about this height, and because this is representative of mesopause heights above which it might be anticipated that the environment in which the waves are propagating changes. Data from all four years of observation are superimposed. The limited number of samples, and the small fraction of usable data from some days of observation, 

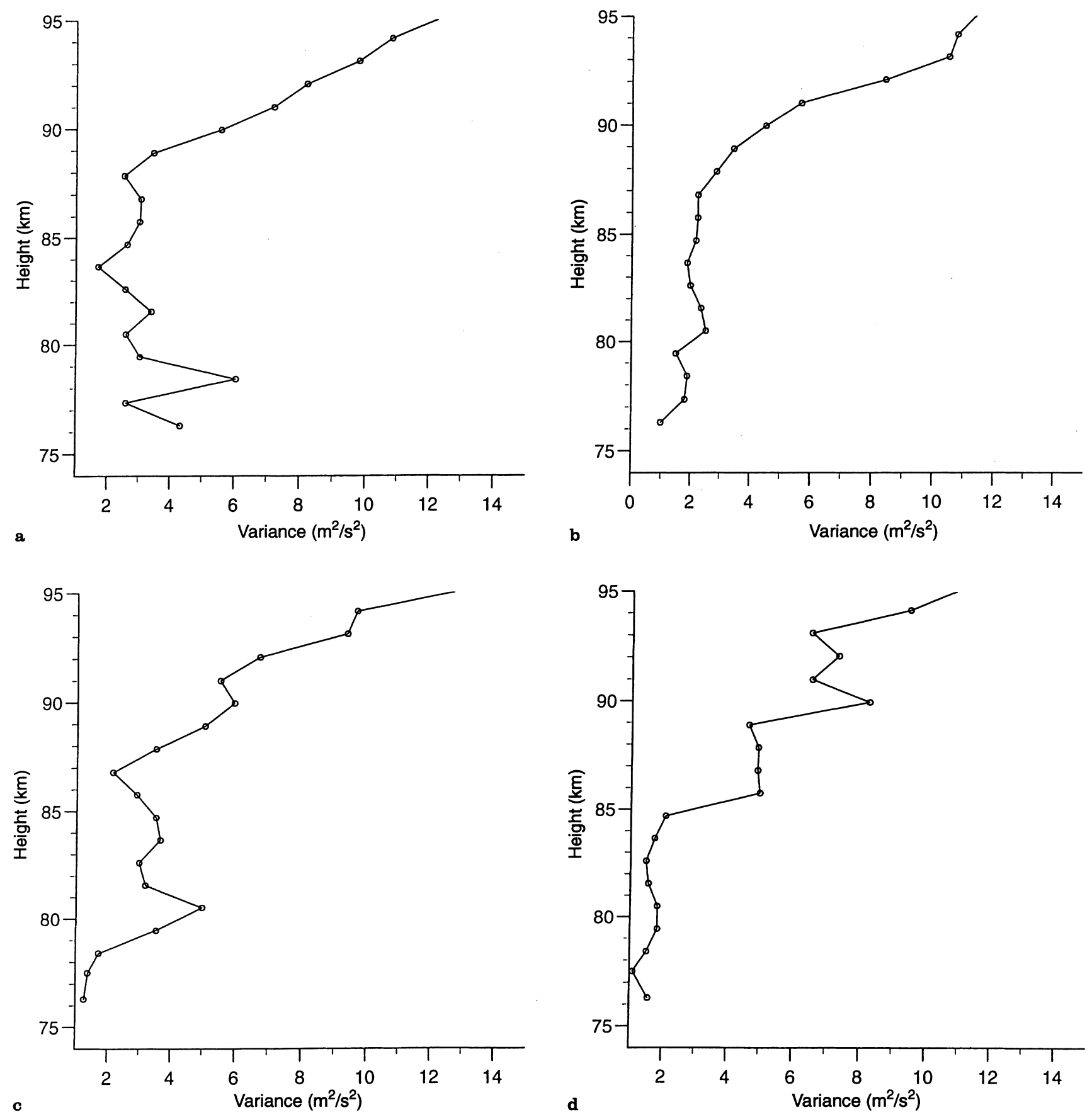

Fig. 5 a-d. Profiles of the daily-mean variance of vertical velocity for four successive days in 1991. a 17 March, b 18 March, c 19 March and d 20 March

introduces uncertainty into any attempt to discern a seasonal cycle. However, there is a suggestion of a winter maximum with mean variances having values up to $6.5 \mathrm{~m}^{2} \mathrm{~s}^{-2}$. Values as low as $1.2 \mathrm{~m}^{2} \mathrm{~s}^{-2}$ are evident around the spring equinox, and a secondary maximum with values up to $5.8 \mathrm{~m}^{2} \mathrm{~s}^{-2}$ is evident near the summer solstice. The situation at the autumnal equinox is less clear, with three data points from October 1992 (day numbers 299, 300, 301) suggesting that a secondary minimum may occur near the autumnal equinox.
A limited number of other studies have measured the vertical profile of vertical-velocity variance at mesopause heights. Fritts and Yuan (1989) used the Poker Flat MST radar over 8 days in July 1986 and found vertical-velocity variances to be approximately constant over the height range $82-87 \mathrm{~km}$, with values of $\sim 6 \mathrm{~m}^{2} \mathrm{~s}^{-2}$ below $87 \mathrm{~km}$. Rüster and Reid (1990) used two days of data recorded by the SOUSY VHF radar in June 1987 at heights between $\sim 83-90 \mathrm{~km}$, and found vertical motions dominated by oscillations with periods of less than one hour and with variances which 

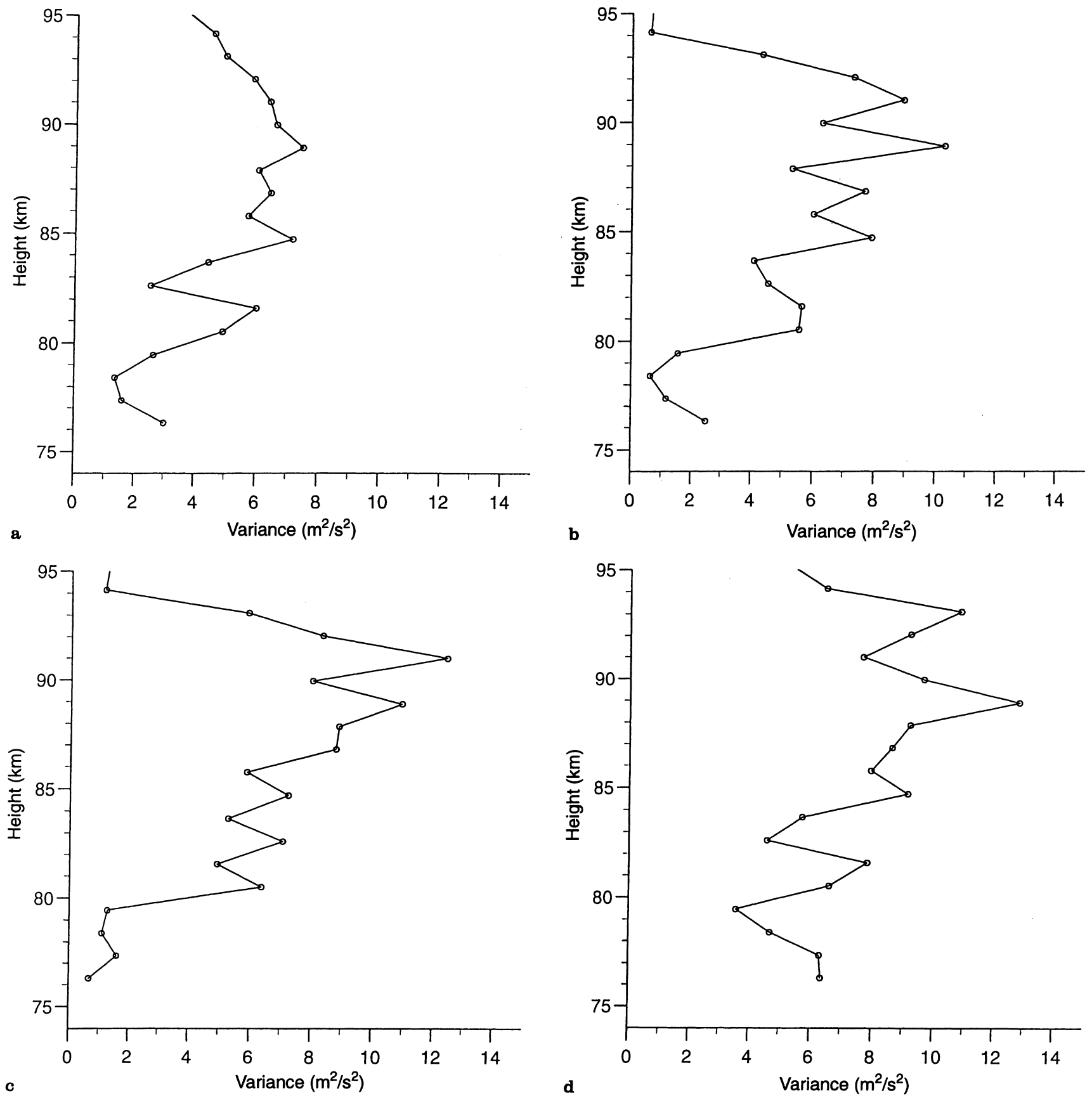

Fig. 6 a-e. Profiles of the daily-mean variance of vertical velocity for four successive days in 1993. a 21 January, b 22 January, c 23 January and d 24 January e 25 January

gradually increased from $\sim 1 \mathrm{~m}^{2} \mathrm{~s}^{-2}$ near $83 \mathrm{~km}$ to $\sim 3$ $\mathrm{m}^{2} \mathrm{~s}^{-2}$ near $90 \mathrm{~km}$. The study of Fritts et al. (1990) reported variances increasing from $\sim 3.5 \mathrm{~m}^{2} \mathrm{~s}^{-2}$ at 81.6 $\mathrm{km}$ to $\sim 6 \mathrm{~m}^{2} \mathrm{~s}^{-2}$ at $90 \mathrm{~km}$ with a mean of $5.2 \mathrm{~m}^{2} \mathrm{~s}^{-2}$ for the $36 \mathrm{~h}$ of measurements made with the EISCATVHF radar (selecting data points with errors of $\leq 0.3$ $\mathrm{m} \mathrm{s}^{-1}$ ), and variances ranging from $\sim 4 \mathrm{~m}^{2} \mathrm{~s}^{-2}$ at $83 \mathrm{~km}$ to $\sim 6 \mathrm{~m}^{2} \mathrm{~s}^{-2}$ at $90 \mathrm{~km}$ with a mean of $5.1 \mathrm{~m}^{2} \mathrm{~s}^{-2}$ for the three days of measurements made by the SOUSY radar.

The variances presented in this study are thus broadly comparable with this earlier work, although it should be noted that the highly variable wave fields described in Sect. 3 and illustrated in Fig. 1a, b suggest that measurements of short duration made only a few hours apart could produce quite different profiles and means of vertical-velocity variance, so direct comparisons should be treated with caution. The persistent shape of the daily mean variance profiles over a number of days is similar to the report of persistent horizontal momentum flux profiles of Fritts et al. (1992) who examined 16 days of data recorded from heights of $\sim 68$ $84 \mathrm{~km}$ using the Jicamara MST radar $\left(12^{\circ} \mathrm{N}\right)$ during summer 1987. A correspondence in momentum flux and 


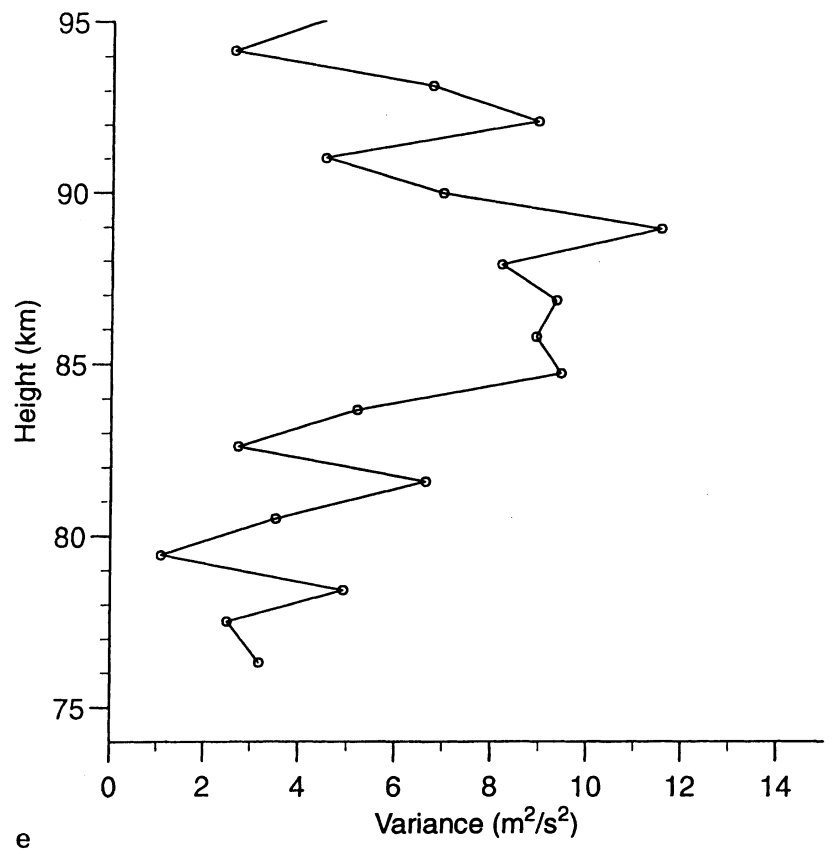

Fig. 6e.

variance profiles is to be expected as it is believed to be the high-frequency waves which make the dominant contribution to the momentum flux, and it is also these waves which make the greatest contribution to the vertical-velocity variance.

A number of sophisticated climatologies of gravity waves at mesopause heights have been constructed from middle or low-latitude measurements of horizon-

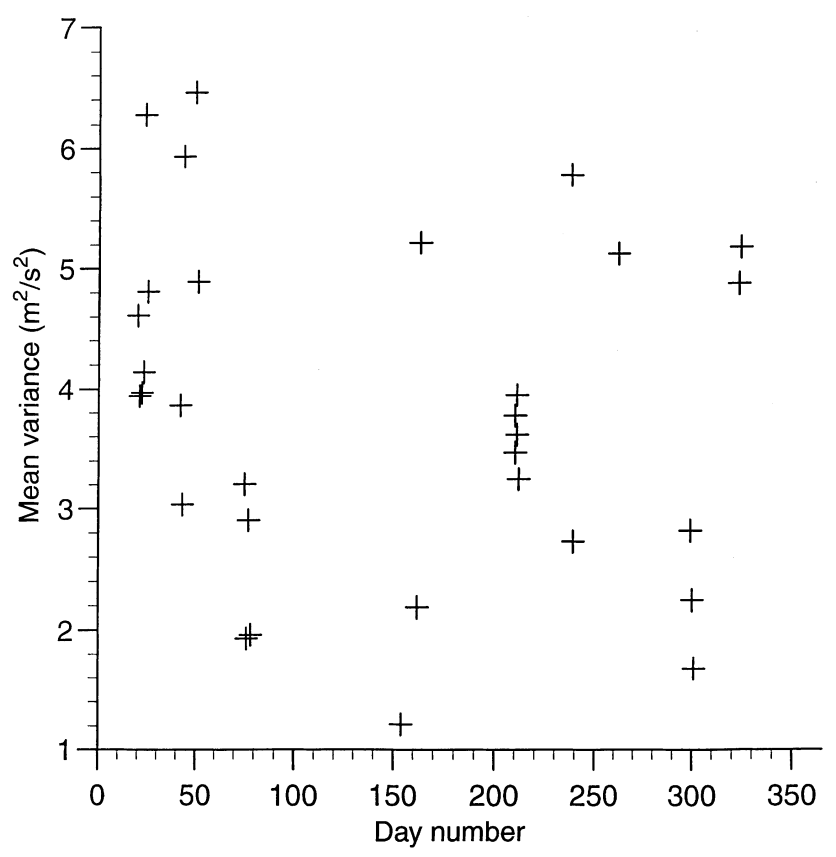

Fig. 7. The daily-mean vertical velocity variance over the height range $76-86 \mathrm{~km}$ for all data tal winds. Climatologies of gravity wave motions at high latitude are much less well developed. MF-radar studies based on horizontal winds have indicated that at mid-latitudes there is an annual cycle for longperiod gravity waves with a winter maximum, whilst at higher wave frequencies (e.g. periods $0.2-2.5 \mathrm{~h}$ ) a marked semi-annual component with a secondary maximum in summer becomes apparent (e.g. Manson and Meek, 1993; Gavrilov et al., 1995; Nakamura et al., 1996).

Our results for the seasonal variation in variance are not in disagreement with the idea that the verticalvelocity field may behave in a similar manner to that of high-frequency gravity waves observed in horizontal velocity measurements. Such a similarity is to be anticipated given the dominant contribution to the vertical velocities made by high-frequency waves (Sect. 3 ) but requires a larger data set than currently available for certainty.

\section{Vertical-wave number spectra}

The vertical-velocity profiles were used to investigate the spectral composition of the wave field in terms of power spectral density as a function of vertical wavenumber, $F_{w}(m)$. In calculating the spectra only data up to heights of $86 \mathrm{~km}$ were considered. This arbitrary upper height limit was chosen in an attempt to avoid spanning the mesopause for the reasons given in Sect. 4, and this restriction limited the number of height gates available to at most 10 (i.e. a $10.5 \mathrm{~km}$ height range). In a significant fraction of the data, fewer points were available for analysis because of episodes of low signal-to-noise in the records. Rather than interpolate over gaps in the individual profiles of vertical velocity, a Lomb-Scargle periodogram was used. This technique allows the spectral analysis of non-periodically spaced data. Spectra were calculated using the periodogram for each individual vertical profile of vertical velocity, then averaged to give a daily-mean spectrum. No attempt was made to try and divide data into cases with and without ducted waves. In the absence of horizontal wind and/or temperature information only the most conspicuous cases (such as that of Figs. 2 and 3) could be identified. The mean spectrum calculated from all the available data in which 9 or 10 height gates satisfied the velocity uncertainty criterion is shown in Fig. 8. Notice that in Fig. 8 there are data points corresponding to spectra calculated over a vertical extend of both $10.5 \mathrm{~km}$ (10 height gates) and $9.45 \mathrm{~km}$ ( 9 height gates).

If the mean spectrum is assumed to have a power-law form, $F_{w}(m) \propto m^{k}$, the spectral index or slope, $k$, is found by a linear regression to be $-1.36 \pm 0.2$. However, the individual daily mean spectra display a considerable range of spectral slopes from $\sim-0.41$ to $\sim-2.25$.

An indication of the range of spectral indices is given in Fig. 9, which presents the daily-mean spectral index against day number; again, data from different years are 


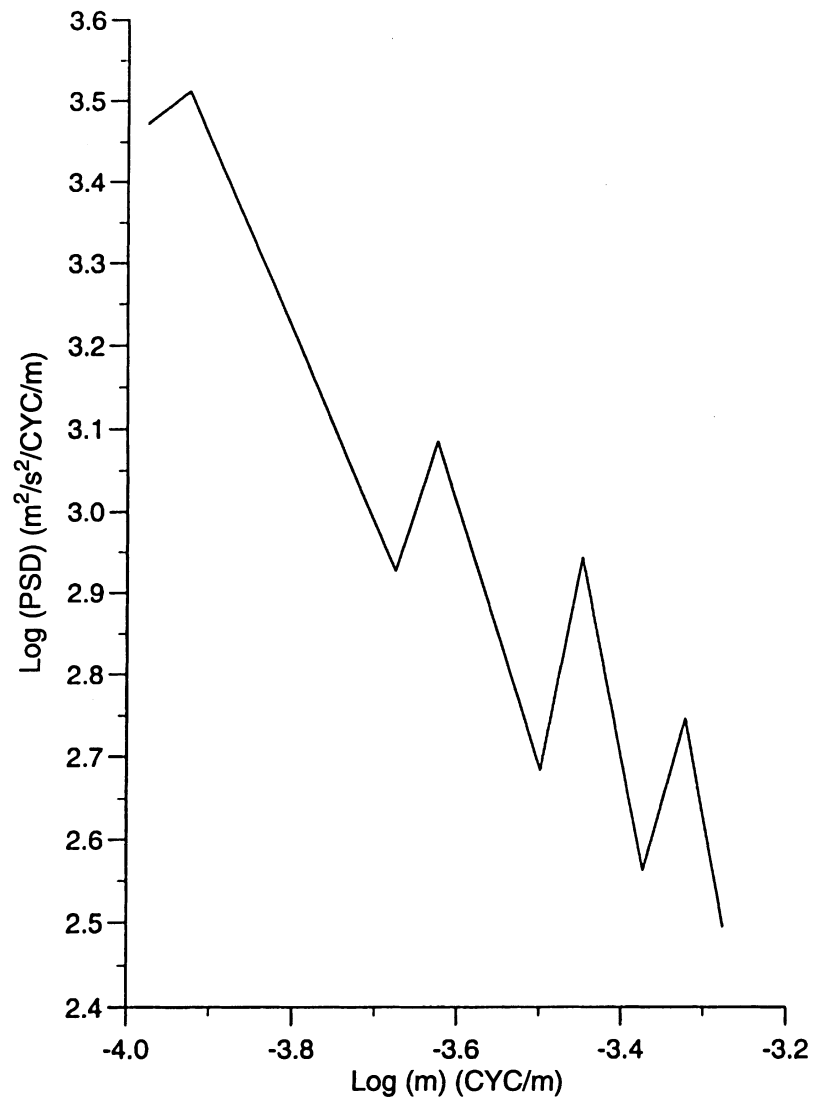

Fig. 8. The mean vertical-wavenumber spectrum of all data over the range $76-86 \mathrm{~km}$. Note that data from spectra calculated with either 9 or 10 data points are included

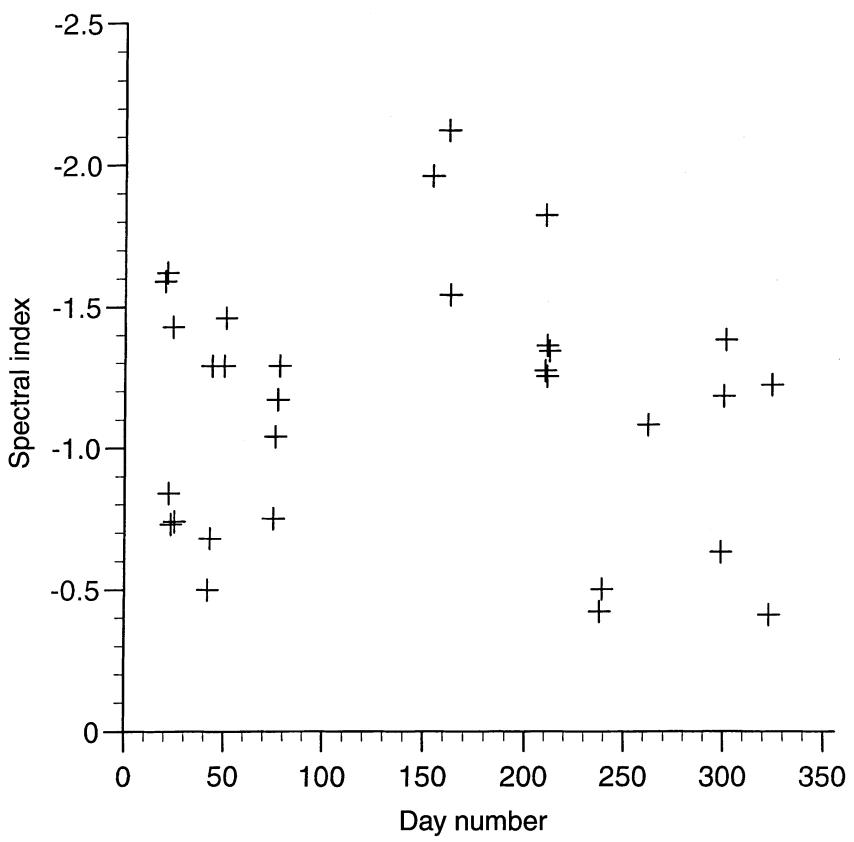

Fig. 9. The daily-mean spectral index (slope) for each of the days of data evaluated over the height range $76-86 \mathrm{~km}$

superimposed. Figure 9 shows a clear trend for the steeper spectral indices to be found in summer and shallower slopes to occur in winter. The equinoctial values are comparable with those of the winter months, although the small number of days of recording prevents definite conclusions. Finally, it should be noted that the wavenumber regime accessible to our analysis is likely to fall entirely within that composed of saturating waves. Typical values for $m_{*}$ (the transitional wave number between saturated and unsaturated waves) reported in studies of horizontal winds at mesopause heights correspond to vertical wavelengths in excess of $15 \mathrm{~km}$ (e.g. Smith et al., 1987).

Finally, we examined the spectral index as a function of the daily-mean variance over the $76-86 \mathrm{~km}$ height range described in Sect. 4. The variation of spectral slope with daily-mean variance is shown in Fig. 10. From this plot it can be seen that there is a tendency for the spectral index to become more positive (i.e. shallower spectral slopes) on days when the mean variance has higher values.

Observations made at lower heights have also investigated spectral slopes at high wavenumbers. The ST-radar studies of Kuo et al. (1985) measured the slopes of vertical-velocity spectra to be near -1.7 in the middle troposphere and near -0.34 in the lower stratosphere. Larsen et al. (1987) reported slopes near -1.3 for troposphere/lower-stratosphere data and Sidi et al. (1988) reported a spectral slope of -1.8 for the lower stratosphere based on a high-resolution balloon measurement. At mesopause heights, Fritts and Hoppe (1995) measured slopes of from $\sim-1$ to $\sim-3$ for two short duration, high-resolution measurements using the EISCAT VHF radar. Gardner et al., (1995) used a Doppler/Sodium lidar to measure vertical wind profiles over 6 hours between heights of $84-100 \mathrm{~km}$ and measured the spectral slope to be -1.4 ; however, in this study the

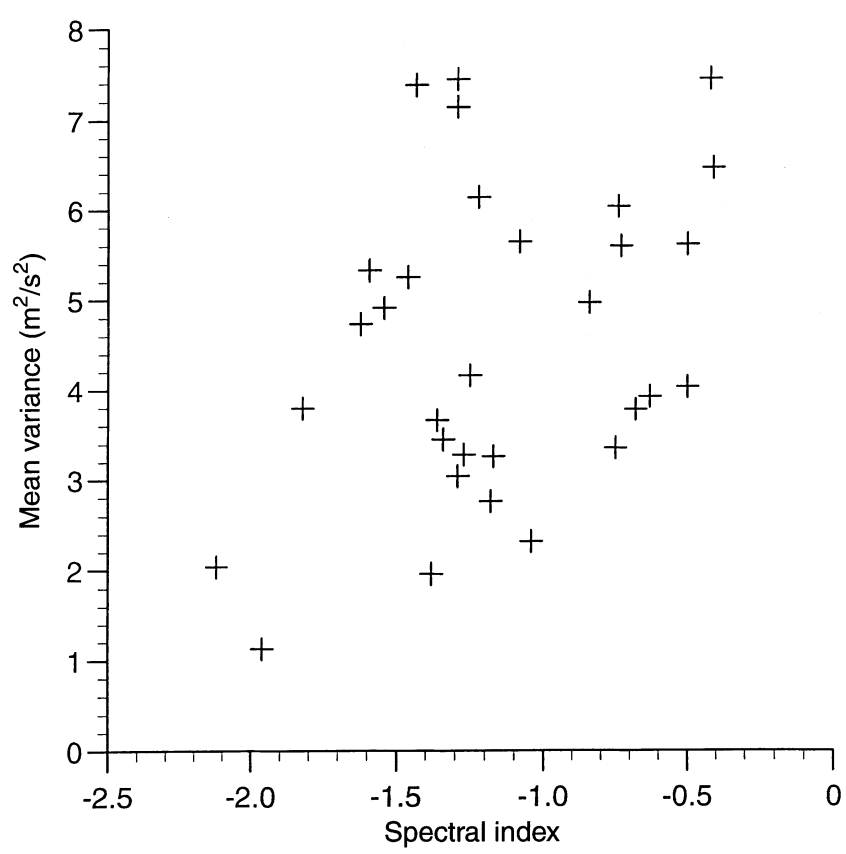

Fig. 10. The spectral index (slope) as a function of daily-mean variance over the height range $76-86 \mathrm{~km}$ 
data was integrated for 20 minutes before spectral analysis, which may have supressed the amplitudes of any high-frequency motions present if of similar periods to those reported here.

A major motivation in studying the vertical-velocity spectra of atmospheric gravity waves is that they offer an opportunity to test theories which have been advanced to explain the observed "universal spectrum" of gravitywave horizontal motions first reported by VanZandt (1982). Gardner (1996) reviewed current theories in some depth, and compared their predictions for a number of atmospheric parameters, including the form of the vertical-wave number spectrum of vertical velocities, $F_{w}(m)$. This parameter is particularly important because, unlike the spectra of horizontal velocities, at least some of the theories predict different behaviour and so allow a test against observation.

The theories invoking linear convective or dynamic instability (Dewan and Good, 1986; Smith et al., 1987) predict a fully separable $(m, \omega)$ spectrum in which the shapes of the horizontal and vertical-velocity wave number spectra, $F_{u}(m)$ and $F_{w}(m)$, respectively, will be identical within the saturated part of the wave spectrum (that which lies at $m$-values above the critical value $m *$ ). There is a considerable, but not unanimous, body of evidence that suggests the $F_{u}(m)$ spectra have slopes close to -3 (e.g. Smith et al., 1987), and so similar values are predicted by this theory for the $F_{w}(m)$ spectra. The diffusive filtering theory of Gardner (1994) predicts that the $(m, \omega)$ spectrum of horizontal winds is not separable and that the vertical-velocity spectra, $F_{w}(m)$, will have a power-law form with slopes $\propto m^{(5-2 p)}$, where $p$ is the spectral index of the frequency spectrum of horizontal winds, and has observationally based values of $p \sim 1.6$ 2. Thus the diffusive filtering theory predicts $F_{w}(m) \propto m$ to $F_{w}(m) \propto m^{1.8}$, i.e., positive spectral slopes of steepness +1 to +1.8 . The saturated cascade theory of Dewan (1994) predicts non-separable $(m, \omega)$ spectra with slopes of about +1 . Neither the diffusive damping theory of Weinstock (1990), nor the Doppler spreading theory of Hines (1991) are as yet sufficiently developed as to be able to make predictions of the vertical-velocity spectral form.

The results presented in our study suggest that the observed spectral slopes of the vertical-velocity spectra are not close to those predicted by any of the theories described already. At all times the spectra have a negative slope, but usually have values between $\sim-0.4$ to $\sim-1.6$; significantly less than predicted by the linear instability theories. However, a complication in the study of the vertical motion field is the probable presence of a population of ducted waves. In cases where there is a significant contribution to the vertical velocities from ducted waves, the spectra may be contaminated by the approximately Gaussian profile of amplitude across the duct (Fig. 3). An assessment of the prevalence of ducted motions is thus essential before the wavenumber spectra of vertical velocity can be used as a definitive test of saturation theories.

\section{Conclusions}

We have presented analysis of 31 days of vertical-wind records made using the EISCAT VHF radar between 12 June, 1990 and 25 January, 1993. The motion field appears to be dominated by high-frequency motions of large vertical wavelength and periods of order 30-40 min. In at least some of the data there are strong indications that waves are trapped in ducts, although additional information about horizontal winds and/or temperatures would be necessary to confirm this suggestion. Such additional information would also be useful in investigating the possible effects of Doppler shifting on the observed waves. The vertical-velocity variances display various forms, but there is little indication of the expected wave growth with height, despite the fact that the dominant waves appear to have very large vertical wavelengths, and so might be expected to belong to the unsaturated part of the spectrum. The persistence of the general form of the vertical profiles of daily mean variance suggests that the wave field is being shaped by longer-lasting properties of the atmosphere, either the background temperature or mean (horizontal) winds, and is similar to that reported in at least one study of the vertical flux of horizontal momentum (Fritts et al., 1992). The seasonal variation in vertical-velocity variance appears to be consistent with the semi-annual cycle reported in studies of shortperiod gravity waves made using observations of horizontal velocity. The spectral properties of the wave field examined over a wave number range which would be expected to be composed of saturated waves agrees with observations made in the troposphere and lowerstratosphere, but do not agree with the predictions of linear instability theory (Dewan and Good, 1986; Smith et al., 1987), diffusive-filtering theory (Gardner, 1994) or saturated-cascade theory (Dewan, 1994). However, the presence of ducted motions within the wave field may seriously contaminate the vertical-wavenumber spectra. This may be an explanation of why the spectra have shallower slopes for wave fields of higher variances (Fig. 10) and again highlights the need for studies in which simultaneous measurements are made of several atmospheric parameters.

Acknowledgements. We are indebted to the Director and staff of EISCAT for operating the facility and supplying the data. EISCAT is an International Association supported by Finland (SA), France (CNRS), the Federal Republic of Germany (MPG), Japan (NIPR), Norway (NFR), Sweden (NFR) and the United Kingdom (PPARC).

Topical Editor D. Alcaydé thanks N. F. Arnold for his help in evaluating this paper.

\section{References}

Chimonas, G., and C. O. Hines, Doppler ducting of atmospheric gravity waves, J. Geophys. Res., 91, 1219-1230, 1986.

Dewan, E. M., The saturated-cascade model for atmospheric gravity-wave spectra, and the wavelength-period (W-P) relations, Geophys. Res. Lett., 21, 817-820, 1994. 
Dewan, E. M., and R. E. Good, Saturation and the "universal" spectrum for vertical profiles of horizontal scalar winds in the atmosphere, J. Geophys. Res., 91, 2742-2748, 1986.

Dunkerton, T. J., Stochastic parametrisation of gravity wave stresses, J. Atmos. Sci., 39, 1711-1725, 1982.

Fritts, D. C., and L. Yuan, Measurement of momentum fluxes near the summer mesopause at Poker Flat, J. Atmos. Sci., 46, 25692579,1989

Fritts, D. C., and U.-P. Hoppe, High-resolution measurements of vertical velocity with the European incoherent scatter VHF radar 2. Spectral observations and model comparisons, $J$. Geophys. Res., 100, 16,827-16,838, 1995.

Fritts, D. C., U.-P. Hoppe, and B. Inhester, A study of the vertical motion field near the high-latitude summer mesopause during MAC/SINE, J. Atmos. Terr. Phys., 52, 927-938, 1990.

Fritts, D. C., and L. Yuan, M. H. Hitchman, L. Coy, E. Kudeki, and R. F. Woodman, Dynamics of the equatorial mesosphere observed using the Jicamara MST radar during June and August 1987, J. Atmos. Sci., 49, 2353-2371, 1992.

Garcia, R. R., Dynamics radiation and photochemistry in the mesophere: implications for the formation of noctilucent clouds, J. Geophys. Res., 94, 14605-14615, 1989.

Gardner, C. S. , Diffusive filtering theory of gravity wave spectra in the atmosphere, J. Geophys. Res., 99, 20601-20622, 1994.

Gardner, C. S., Testing theories of atmospheric gravity-wave saturation and dissipation, J. Atmos. Terr. Phys., 58, 15751589, 1996.

Gardner, C. S., M. S. Miller, and C. H. Lui, Rayleigh lidar observations of gravity wave activity in the upper stratosphere at Urbana, Illinois, J. Atmos. Sci., 46, 1838-1854, 1989.

Gardner, C. S., X. Tao, and G. C. Papen, Simultaneous lidar observations of vertical wind, temperature and density profiles in the upper mesosphere: evidence for nonseperability of atmospheric perturbation spectra, Geophys. Res. Lett., 22 , 2877-2880, 1995.

Gavrilov, N. M., A. H. Manson, and C. E. Meek, Climatological monthly characteristics of middle atmosphere gravity waves (10 min-10 h) during 1979-1993 at Saskatoon, Ann. Geophysicae, 13, 285-295, 1995

Hines, C. O., The saturation of gravity waves in the middle atmosphere, II. Development of Doppler-spread theory, $J$. Atmos. Sci., 48, 1360-1379, 1991.

Hines, C. O., Doppler-spread parametrization of gravity-wave momentum deposition in the middle atmosphere. 1. Basic formulation, J. Atmos. Terr. Sol. Terr. Phys., 59, 371-386, 1997a.

Hines, C. O., Doppler-spread parametrization of gravity-wave momentum deposition in the middle atmosphere. 2. Broad and quasi monochromatic spectra and implementation, J. Atmos. Terr. Sol. Terr. Phys., 59, 387-400, 1997b.

Holton, J. R., The role of gravity-wave induced drag and diffusion in the momentum budget of the mesosphere, J. Atmos. Sci., 39, 791-799, 1982.

Holton, J. R., The influence of gravity-wave breaking on the general circulation of the middle atmosphere, J. Atmos. Sci., $\mathbf{4 0}$, 2497-2507, 1983

Holton, J. R., and X. Zhu, A further study of gravity wave induced drag and diffusion in the mesosphere, J. Atmos. Sci., 41, 2653$2662,1984$.

Hoppe, U.-P., and D. C. Fritts, High-resolution measurements of vertical velocity with the European incoherent scatter VHF radar 1. Motion field characteristics and measurement biases, $J$. Geophys. Res., 100, 16813-16825, 1995.

Houghton, J. T., The stratosphere and mesosphere, Q. J. Meteorol. Soc., 104, 1-29, 1978.

Kuo, F. S., H. W. Shen, I. J. Fu, J. K. Chao, J. Rottger, and C. H. Liu, Altitude dependence of vertical velocity spectra observed by VHF radar, Radio. Sci., 20, 1349-1354, 1985.

Larsen, M. F., J. Rottger, and D. N. Holden, Direct measurements of vertical-velocity power spectra with the SOUSY-VHF-radar wind profiler system, J. Atmos. Sci., 44, 3442-3448, 1987.
Lindzen, R. S., Turbulence and stress due to gravity wave and tidal breakdown, J. Geophys. Res., 86, 9707-9714, 1981.

McIntyre, M. E., On dynamics and transport near the polar mesopause in summer, J. Geophys. Res., 94, 14617-14628, 1989.

Manson, A. H., Gravity wave horizontal and vertical wavelengths; an update of measurements in the mesopause region $(\sim 80$ $100 \mathrm{~km})$. J. Atmos. Sci., 47, 2765-2773, 1990.

Manson, A. H., and C. E. Meek, Characteristics of gravity waves (10 min-6 hours) at Saskatoon $\left(52^{\circ} \mathrm{N}, 107^{\circ} \mathrm{W}\right)$ observed by the phase coherent medium frequency radar, J. Geophys. Res., 98, 20357-20367, 1993.

Matsuno, T., A quasi-one dimensional model of the middle atmospheric circulation interacting with internal gravity waves, J. Meteorol. Soc. Japan, 60, 215-226, 1982.

Meek, C. E, and A. H. Manson, Vertical motions in the upper middle atmosphere from the Saskatoon $\left(52^{\circ} \mathrm{N}, 107^{\circ} \mathrm{W}\right)$ M.F. radar, J. Atmos. Sci., 46, 849-858, 1989.

Meek, C. E, I. M. Reid, and A. H. Manson, Observations of mesospheric wind velocities Part I: gravity wave horizontal scales and phase velocities determined by spaced wind observations, Radio Sci., 20, 1363-1382, 1985a.

Meek, C. E, I. M. Reid, and A. H. Manson, Observations of mesospheric wind velocities Part II: cross sections of power spectral density for $48-8 \mathrm{~h}, 8-1 \mathrm{~h}, 1 \mathrm{~h}-10$ min over $60-110 \mathrm{~km}$ for 1981, Radio Sci., 20, 1383-1402, 1985b

Meriwether, J. W., Lidar observation of atmospheric dynamics in the troposphere and lower stratosphere over Arecibo, $J$. Geophys. Res., 98, 20713-20723, 1993.

Meriwether, J. W., P. D. Dao, R. T. McNutt, and W. Klemetti, Rayleigh lidar observations of mesosphere temperature structure, J. Geophys. Res., 99, 16973-16987, 1994.

Mitchell, N. J, L. Thomas, and A. K. Marsh, Lidar observations of long-period gravity waves in the stratosphere, Ann. Geophysicae, 9, 588-596, 1991.

Mitchell, N. J., L. Thomas, and I. T. Prichard, Gravity waves in the stratosphere and troposphere observed by lidar and MST radar, J. Atmos, Terr. Phys., 56, 939-947, 1994.

Miyahara, S., A numerical simulation of the zonal mean circulation of the middle atmosphere including effects of solar diurnal tidal waves and internal gravity waves: solstice conditions, in Dynamics of the Middle Atmosphere, Eds. Holton, J. R. and T. Matsuno, pp. 271-287, 1984.

Nakamura, T., T. Tsuda, M. Yamamoto, S. Fukao, and S. Kato, Characteristics of gravity waves in the mesosphere observed with the middle and upper atmosphere radar, J. Geophys. Res. 96, 8899-8910, 1993.

Nakamura, T., T. Tsuda, S. Fukao, A. H. Manson, C. E. Meek, R. A. Vincent, and I. M. Reid, Mesospheric gravity waves at Saskatoon $\left(52^{\circ} \mathrm{N}\right)$, Kyoto $\left(35^{\circ} \mathrm{N}\right)$ and Adelaide $\left(35^{\circ} \mathrm{S}\right), J$. Geophys. Res., 101, 3, 7005-7012, 1996.

Reid, I. M., Some aspects of Doppler radar measurements of the mean and fluctuating components of the wind field in the upper middle atmosphere, J. Atmos, Terr. Phys., 45, 467-484, 1987.

Rüster, R., and I. M. Reid, VHF radar observations of the dynamics of the summer polar mesopause region, J. Geophys. Res., 95, 10005-10016, 1990.

Senft, D. C., C. A. Hostetler, and C. S. Gardner, Characteristics of gravity-wave activity and spectra in the upper stratosphere and upper mesosphere at Areceibo during early April 1989, J. Atmos. Terr. Phys., 55, 425-439, 1993.

Sidi, C., J. Lefrere, F. Dalaudier, and J. Barat, An improved atmospheric buoyancy wave spectrum model, J. Geophys. Res., 93, 774-790, 1988

Smith, S. A., D. C. Fritts, and T. E. VanZandt, Evidence for a saturated spectrum of atmospheric gravity waves, J. Atmos. Sci., 44, 1404-1410, 1987.

Taylor, M. J., D. C. Fritts, and J. R. Isler, Determination of horizontal and vertical structure of an unusual pattern of shortperiod gravity waves imaged during ALOHA-93, Geophys. Res. Lett., 22, 20, 2837-2840, 1995. 
VanZandt, T. E., A universal spectrum of buoyancy waves in the atmosphere, Geophys. Res. Lett., 9, 575-578, 1982.

Vincent, R. A., and D. C. Fritts, A climatology of gravity wave motions in the mesopause region at Adelaide, Australia, $J$. Atmos. Sci., 44, 748-760, 1987.

Vincent, R. A., and I. M. Reid, HF Doppler measurements of mesospheric gravity wave momentum fluxes, J. Atmos. Sci., 40, 1321-1333, 1983.
Weinstock, J., Saturated and unsaturated spectra of gravity waves and scale-dependent diffusion, J. Atmos. Sci., 47, 2211-2225, 1990.

Wilson, R. A., A. Hauchecorne, and M.-L. Chanin, Gravity waves in the middle atmosphere observed by Rayleigh lidar, I. Case studies, J. Geophys. Res., 96, 5153-5168, 1991. 